\title{
Hybridization results in high levels of sterility and restricted introgression between invasive and endemic marine blue mussels
}

\author{
Pamela M. Brannock*, Thomas J. Hilbish \\ Department of Biological Sciences, University of South Carolina, 715 Sumter Street, Columbia, South Carolina 29208, USA
}

\begin{abstract}
Species in the blue mussel species-complex (Mytilus edulis, M. trossulus, and M. galloprovincialis) readily hybridize, but the level of introgression depends upon which species are sympatric. Hybridization between the native pan-Pacific mussel $M$. trossulus and the invasive Mediterranean mussel $M$. galloprovincialis typically results in limited introgression. We show that gender of hybrid mussels frequently cannot be determined in 2 hybrid zones formed between these species in Hokkaido, Japan. Hybrid individuals produce gametic tissue and have levels of reproductive effort similar to those of the pure species, but unlike the parental species, gametogenesis fails to produce mature gametes similar to those hybrid males or females. A majority of the gametic cells in hybrid individuals appear to be arrested in an early state of maturation, and rarely produce viable gametes. High levels of sterility afflict both $\mathrm{F}_{1}$ and other hybrid individuals (putative $\mathrm{F}_{2}$ and backcross individuals) forming a potent mechanism of reproductive isolation. While the incidence is greatly reduced, $\mathrm{F}_{1}$ and other hybrids do produce mature gametes, resulting in low levels of introgression. Unsuccessful gametogenesis of hybrid mussels is likely a general phenomenon that limits introgression in the northern Pacific where the Mediterranean mussel has been introduced.
\end{abstract}

KEY WORDS: Hybrid zone $\cdot$ Reproductive isolation $\cdot$ Post-zygotic isolation $\cdot$ Mytilus $\cdot$ Blue mussel Resale or republication not permitted without written consent of the publisher

\section{INTRODUCTION}

The mechanisms of speciation in marine ecosystems remain of interest due to the lack of obvious barriers to gene flow, especially for species with protracted larval dispersal (Palumbi 1992, 1994). Many marine species spawn gametes into the water column, and fertilization occurs externally; thus, there is relatively little opportunity to develop pre-mating reproductive barriers based upon mate recognition. Consequently, research on speciation in marine systems has focused on the evolution of gamete recognition as a potential mechanism producing pre-mating reproductive isolation (McCartney \& Lessios 2002, Swanson \& Vacquier 2002, Rawson et al. 2003, Riginos \& McDonald 2003, Riginos et al. 2006, Springer \& Crespi 2007, Styan et al. 2008).

The role of post-mating reproductive isolating mechanisms (i.e. hybrid inviability, hybrid sterility, and hybrid breakdown) in speciation of marine organisms, however, has seldom been examined due to long generation times and other difficulties in rearing and maintaining marine organisms in a laboratory setting (Palumbi 1994). Post-mating isolations are important not only because they are among mechanisms that may maintain species integrity, but are often important in the maintenance of hybrid zones (Barton \& Hewitt 1985). Decreased fitness among hybrids may result in the formation of a tension zone, where the structure and position of the hybrid zone is determined by the genetic incompatibilities between 2 species (Barton 1979, Barton \& Hewitt 1985), as opposed to natural selection governed by the interaction of specific hybrid genotypes and the distribution of environmental variables ('bounded hybrid superiority' or hybrid mosaic) (Moore 1977, Harrison \& Rand 1989). Breakdown of fitness or fecundity of hybrids formed between 2 species comprises initial evidence that a hybrid zone is maintained as a tension zone (Barton \& Hewitt 1985). 
Marine mussels in the Mytilus edulis complex ( $M$. edulis, $M$. trossulus, and $M$. galloprovincialis) are emerging as a model system for examining the role of post-mating reproductive isolation in limiting hybridization and introgression (Brannock et al. 2009). Species within this complex are capable of interbreeding when sympatric (Gosling 1992) and exhibit different propensities for hybridization and introgression depending on the species involved and the conditions under which they became sympatric (Brannock et al. 2009). The 2 sister taxa, M. edulis and M. galloprovincialis, hybridize freely (Wilhelm \& Hilbish 1998) and form an extensive hybrid complex in Europe that has resulted in substantial introgression (Rawson \& Hilbish 1998). In contrast, when either of these species is sympatric with $M$. trossulus, hybridization does occur, but introgression is generally limited (Rawson et al. 1999, Anderson et al. 2002, Toro et al. 2004, Riginos \& Cunningham 2005, Brannock et al. 2009). Natural hybridization occurs between $M$. trossulus and $M$. edulis in the northwestern Atlantic (Comesaña et al. 1999, Rawson et al. 2001, Riginos \& Cunningham 2005) and highly localized hybridization occurs between these species as a result of species introduction in the Georgia Strait in British Columbia (Heath et al. 1995) and Loch Etive in Scotland (Beaumont et al. 2008). In contrast, M. galloprovincialis is a highly invasive species (Lowe et al. 2000) and has been repeatedly introduced within the range of $M$. trossulus resulting in extensive hybrid zones in California (McDonald \& Koehn 1988, Rawson et al. 1999), Puget Sound (Anderson et al. 2002), Russia (Skurikhina et al. 2001), and Japan (Inoue et al. 1997, Brannock et al. 2009). Brannock et al. (2009) recently demonstrated that hybrid zones between $M$. galloprovincialis and $M$. trossulus in northern Japan have 2 conspicuous features. First, $F_{1}$ hybrids occur in Japan at extraordinary levels, far exceeding expectations based upon random mating, suggesting that the incompatibilities in gamete recognition are weak or non-existent and certainly are not limiting the formation of $F_{1}$ hybrids. This finding is consistent with previous laboratory studies, which report no difficulties in the formation of $F_{1}$ hybrids from M. galloprovincialis and M. trossulus crosses (Matson et al. 2003). Second, despite the preponderance of $F_{1}$ hybrids in Japan, there is little introgression beyond the formation of $F_{1}$ hybrids (Brannock et al. 2009). Futhermore, hybridization between these mussels has occurred in northern Japan for over a decade (Inoue et al. 1997), making the low level of introgression even more striking because sufficient time has passed for hybridization to proceed beyond the first 2 generations. This result is consistent with all previous studies of hybridization between $M$. galloprovincialis and $M$. trossulus; there is minimal evidence that hybridization results in substantial introgression beyond the formation of $F_{1}$ hybrids (Rawson et al. 1999, Anderson et al. 2002, Wonham 2004, Elliott et al. 2008, Brannock et al. 2009). These observations strongly suggest the operation of post-zygotic selection in determining the level of introgression between these species and in shaping their hybrid zone characteristics.

We assessed gender of mussels from different regions of Hokkaido, Japan, utilizing conventional field techniques, and noted that within the 2 hybrid zones described by Brannock et al. (2009), gender indeterminate individuals occurred at frequencies far higher than in non-hybridizing regions containing either parental species. This observation suggested the hypothesis that hybridization may result in some form of disruption of normal gametogenesis and thus contribute to post-zygotic reproductive isolation between Mytilus galloprovincialis and $M$. trossulus. Here we demonstrate that hybrids between $M$. galloprovincialis and $M$. trossulus in northern Japan begin gametogenesis but rarely produce mature gametes. Disruption of gametogenesis in hybrids provides a potent mechanism for post-mating reproductive isolation that restricts introgression between these species.

\section{MATERIALS AND METHODS}

Sample collection. Approximately 50 blue mussels were collected from each of 19 locations (Fukushima: FK; Kaminokuni: KM; Suttsu: SU; Yoichi Cape: YO; Hamamasu: HA; Shosanbetsu: SHO; Hamatonbetsu: HM; Saruru: SR; Lake Notoro Inner: LNI; Abashiri: AB; Utoro: UT; Nemuro: NE; Akkeshi Intertidal: AI; Shoya: SY; Niikappu: NP; Tomakomai: TO; Muroran Marine Station: MR; Toyako Town: TY; Toi: TI) around Hokkaido, Japan in May and June 2008 (Fig. 1). These locations are a subset of those sampled by Brannock et al. (2009). We assessed the gender of individual mussels ( $\geq 15 \mathrm{~mm}$ in shell length) in the field by gonad squashes and microscopic examination $(100 \times$ and $400 \times$ magnification) of the mantle center. In mussels the mantle serves as the principal site of gametogenesis and thus serves multiple functions, including acting as the gonad (Lowe et al. 1982). An individual's gender was determined to be female if eggs and male if sperm (motile) were visible by microscope examination of the gonad tissue. If neither eggs nor sperm were visible, the individual was classified as gender indeterminate. A piece of the mantle edge and mantle center (gonad) tissue was preserved in $95 \%$ ethanol for genetic analysis. If the gender of an individual could not be determined in the field (gender indeterminate) an additional piece of mantle center tissue was preserved in paraformaldehyde (diluted in buffered sea water) for 


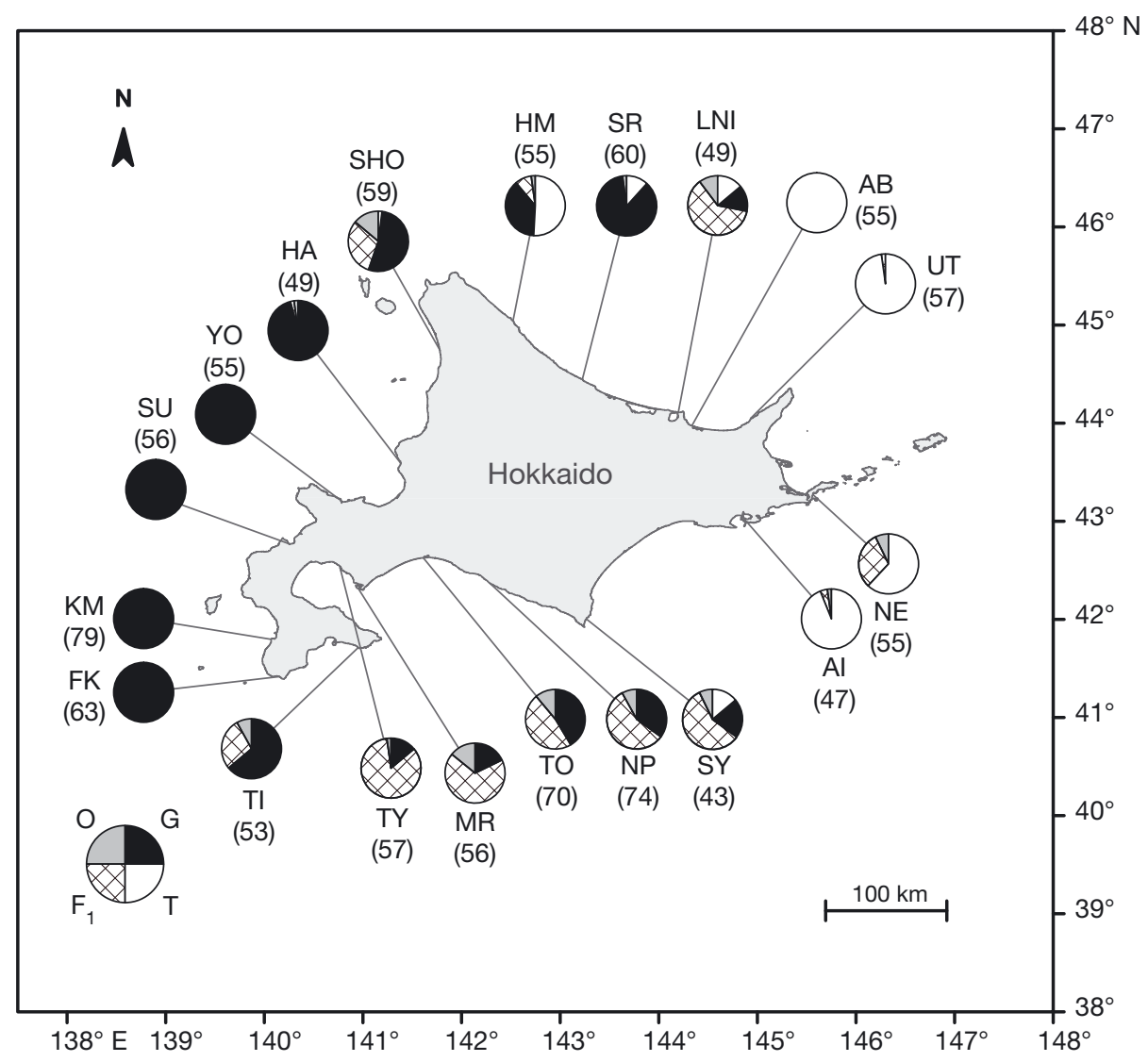

Fig. 1. Mytilus galloprovincialis and M. trossulus. Geographic distribution of M. galloprovincialis (black, G), M. trossulus (white, T), $F_{1}$ hybrids (cross-hatched, $F_{1}$ ), and other hybrid (gray, O) individuals around Hokkaido, Japan in 2008. Sample sizes reported in parentheses. Site codes are given in 'Materials and methods: Sample collection'

histological analysis. Two locations TO and NP, were re-sampled $4 \mathrm{wk}$ after the initial collection and another 20 to 25 individuals were assessed for gender.

Genetic analysis. Total genomic DNA was extracted following the protocol in Rawson et al. (1999). Individuals were assayed using 3 single-locus nuclear genetic markers (Glu-5', ITS, and Mal-I) by polymerase chain reaction (PCR) as described in Brannock et al. (2009). All 3 markers completely differentiate between $M Y$ tilus galloprovincialis and $M$. trossulus (Heath et al. 1995, Inoue et al. 1995, Rawson et al. 1996a,b, 1999). Individuals were classified as M. galloprovincialis or M. trossulus if they were homozygous at all 3 loci for alleles diagnostic of each respective species. Individuals were classified as $F_{1}$ hybrids if they were heterozygous for alleles from each of the 2 species at all 3 loci. The final category of 'other hybrids' consisted of individuals that exhibited multi-locus genotypes that do not fit into the 3 other categories. These individuals were assumed to be the progeny of hybrid crosses beyond $F_{1}$ hybrid (e.g. backcrosses and $F_{2}$ ), and will hereafter be referred to as 'other hybrids'. Only indi- viduals that were successfully assayed at all 3 nuclear loci were categorized. We recognize that there is error in assigning individuals into distinct genealogical classes in this fashion. For example, among individuals which are heterozygous at all 3 diagnostic loci, the majority probably belong to the $\mathrm{F}_{1}$ genealogical class, but this genotypic category may also contain a fraction of individuals that belong to $\mathrm{F}_{2}$ and first and secondgeneration backcross genealogical classes (Nason \& Ellstrand 1993, Boecklen \& Howard 1997). The probability of misclassification depends upon the true genealogical composition of a population, but is generally small; therefore, we have ignored this potential source of error in this study. Unless otherwise specified, the term hybrids refers to the combined genealogical classes of $F_{1}$ hybrids and other hybrids.

Histological procedures. Gender indeterminate individuals were common in both the northern and southern hybrid zones (see 'Results') described by Brannock et al. (2009). To test whether the high incidence of gender indetermination was related to the genealogical composition of these populations, histo- 
logical analysis was performed. A random selection of 10 gender determinate and another of 10 gender indeterminate individuals from each of the 4 genealogical classes (Mytilus galloprovincialis, M. trossulus, $\mathrm{F}_{1}$ hybrid, and other hybrid genotypes) were histologically analyzed. We focused on southern Hokkaido between TI and NE (Fig. 1) because this region has the highest frequency of hybrids observed in Hokkaido in addition to containing each of the parental species (Brannock et al. 2009). In some cases, there were fewer than 10 individuals available for inclusion in a treatment group or, upon histological examination, an individual proved to be parasitized and was excluded from the analysis. Thus, sample sizes did not always equal 10 in each group. Furthermore, upon histological examination of the gender indeterminate individuals, gender of those individuals was recorded. Individuals were classified as female if the reproductive follicles contained eggs (mature or immature) and male if the reproductive follicle contained any stage of sperm production from spermatogonia to spermatids.

We first tested whether preservation of the mantle tissue affected the thickness or gametogenic composition of the tissue by comparing tissue samples from the same individual that had been preserved in paraformaldehye vs. $95 \%$ ethanol. There was no apparent effect of preservation method on either mantle thickness or gametogenic composition (data not shown) and thus we prepared tissue samples for histological analysis that had been preserved in $95 \%$ ethanol using protocols identical to those used for tissues preserved in paraformaldehyde. The thickness of the preserved mantle center tissue was measured $( \pm 0.05 \mathrm{~mm})$ under a dissecting scope prior to histological analysis. Mantle tissue samples were embedded in paraffin, cut into $5 \mu \mathrm{m}$ sections, and stained with hematoxylin and counterstained with eosin (H\&E) at the University of South Carolina Medical School Instrumental Resource Facility. Slides were examined under an Olympus BH-2 compound light microscope with apochromatic lenses and 100 randomly selected cells per individual were assayed for cell type and cell measurement using a camera lucida. Cells were identified as vesicular connective tissue cells (VCT), adipogranular cells (ADG), mature gametes, immature gametes, or follicular space (empty space within the follicle) as per Lowe et al. (1982). VCT and ADG cells, respectively, contain glycogen and proteins that are used to fuel gametogenesis in mussels (Lowe et al. 1982). Females and males were examined under $100 \times$ and $400 \times$ magnification, respectively. Outlines of the mature and immature eggs were traced and used to estimate the area of each gamete by assuming the gamete was an oval. In males, the diameter of mature and immature sperm was measured. In addition to measuring the frequency of each cell type in an individual, we also combined the frequency of mature and immature gametes to estimate the total fraction of the mantle devoted to gametes (e.g. gamete volume fraction, GVF). In addition, the percentage of the GVF that was mature and immature gametic tissue was also calculated.

Statistical analysis. Samples from NE showed a high proportion of individuals with disseminated neoplasia (Peters 1988, Elston et al. 1992) and a majority of the individuals examined histologically did not contain any reproductive or VCT and ADG storage tissues. Consequently we eliminated all individuals collected from NE from all subsequent analyses. Since natural mussel populations usually do not significantly deviate from a 1:1 sex ratio (Hilbish \& Zimmerman 1988, Fisher \& Skibinski 1990, Zouros et al. 1994), we used a chisquare $\left(\chi^{2}\right)$ test to determine whether the populations surveyed in this study (both together by geographic location and separately) significantly departed from a 1:1 sex ratio. To determine whether the frequency of gender determinate individuals in the field depended upon the genetic composition of the populations, we divided the sampled locations into those dominated by Mytilus galloprovincialis in western Hokkaido (FK, $\mathrm{KM}, \mathrm{SU}, \mathrm{YO}, \mathrm{HA})$, by $M$. trossulus in the east (AB, UT, $\mathrm{AI})$, and the northern (SHO, HM, SR, LNI) and southern (TI, TY, MR, TO, NP, SY) hybrid zones previously described by Brannock et al. (2009). We then used a $G$ test of independence (Sokal \& Rohlf 1995) to determine whether the ratio of gender determinate to indeterminate mussels depended upon geographic region. Since TO and NP populations were sampled twice, a G-test of independence (Sokal \& Rohlf 1995) was utilized to determine whether there was a significant difference in the ratio of gender determinate to indeterminate individuals between the 2 sample dates. Histological data were analyzed by analysis of variance (ANOVA) to test whether GVF, mantle thickness, and gamete maturity (mature:immature ratio) depended upon gender, gender determination in the field, and genealogical classification. Multiple comparisons among the means of GVF, mantle thickness, and gamete maturity in reference to genealogical classes were conducted utilizing the Bonferroni method. For all statistical tests, experimentwise $\alpha$ was set at 0.05 .

\section{RESULTS}

A total of 1111 blue mussels were collected from 19 locations around Hokkaido in May and June 2008, and $98.3 \%$ were successfully assayed at all 3 nuclear loci and assigned to 1 of the 4 genealogical classes (Mytilus galloprovincialis, $M$. trossulus, $\mathrm{F}_{1}$ hybrid, and other hybrid) (Fig. 1). M. galloprovincialis dominated the 
western Hokkaido coast, $M$. trossulus was more prevalent in the eastern portion of the island, and hybridization between the species occurred along both the northern and southern Hokkaido coast (Fig. 1). The majority $(71 \%)$ of the hybrid individuals were found within the southern Hokkaido hybrid zone from TI to SY. All other geographic locations in Hokkaido contained considerably lower levels of hybrid individuals (west: $1 \%$, east: $8 \%$, and north: $20 \%$ ). Of all the hybrids, $83.5 \%$ were classified as $\mathrm{F}_{1}$ hybrids.

\section{Gender determination in the field}

Gender was successfully determined in the field for $79 \%$ of the individuals. There was no significant difference $\left(\chi^{2}=1.28, p=0.26\right)$ from a $1: 1$ male $(52.7 \%)$ to female $(47.3 \%)$ sex ratio for all gender determined individuals collected around Hokkaido in 2008. The fraction of gender determinate individuals in the field was strongly dependent upon geographic region $(G=$ 189.4, df $=3, \mathrm{p}<0.001$ ) (Fig. 2A). In the southern Hokkaido hybrid zone, $57.2 \%$ of the individuals were gender determinate while in the northern hybrid zone, $81.6 \%$ of the individuals were gender determinate (Fig. 2A). In regions where Mytilus galloprovincialis and $M$. trossulus dominated (western and eastern Hokkaido), 92.1 and $99.4 \%$ of individuals were gender determinate, respectively (Fig. 2A). Furthermore, the frequency of gender determinate individuals within a region was negatively correlated with the frequency of hybrids $(r=-0.979, \mathrm{p}<0.05)$.

The significantly lower frequency of gender determinate individuals in both hybrid zones suggests that hybrids may have lower success in maturation than either of the parental species. To test this hypothesis we compared the frequency of gender determinate individuals among the 4 genealogical classes within the northern and southern hybrid zones. The frequency of gender determinate individuals was highly dependent on the genealogical classification in both the northern $(G=62.36, \mathrm{df}=3, \mathrm{p}<0.001)$ and southern ( $G=167.86, \mathrm{df}=3, \mathrm{p}<0.001$ ) hybrid zones (Fig. 2B). In both hybrid zones, the frequency of gender determinate individuals that were hybrids was less than half of that in individuals classified as Mytilus galloprovincialis or $M$. trossulus (Fig. 2B). There was no significant difference in the frequency of gender determinate individuals between mussels classified as M. galloprovincialis and $M$. trossulus in either the northern $(G=0.78, \mathrm{df}=1, \mathrm{p}=0.380)$ or southern $(G=2.94$, $\mathrm{df}=$ $1, \mathrm{p}=0.087$ ) hybrid zone (Fig. 2B). Likewise, there was also no significant difference in the frequency of gender determinate individuals classified as $F_{1}$ hybrids or other hybrids in either the northern $(G=0.09$, df $=1$,

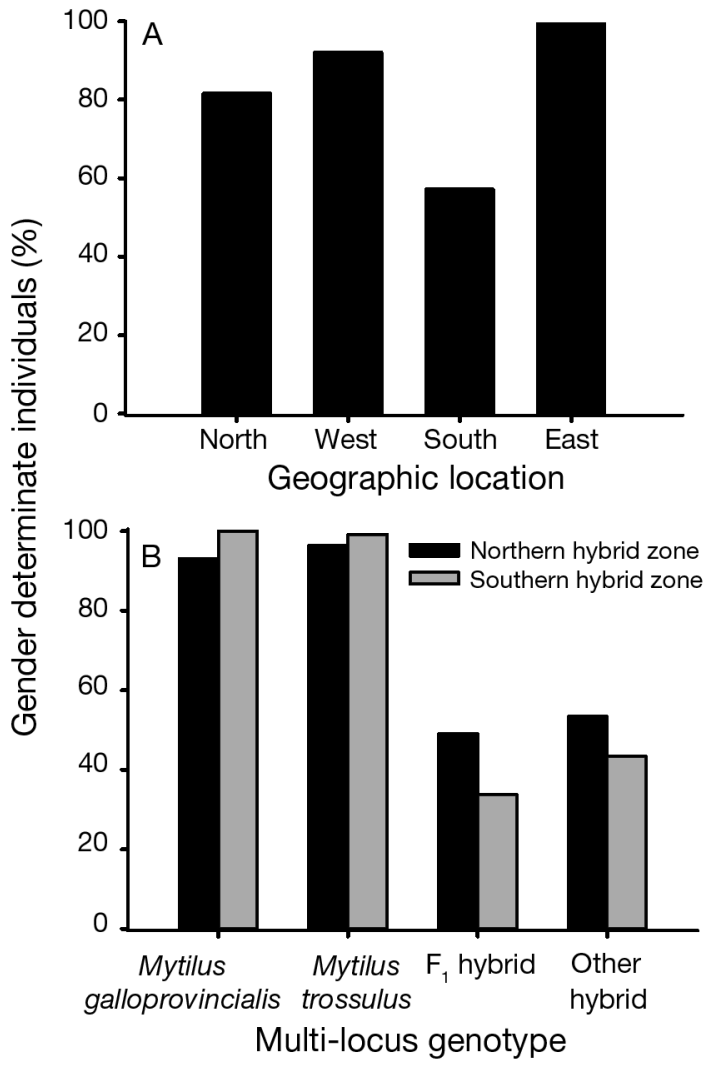

Fig. 2. Mytilus galloprovincialis and M. trossulus. Total percentage of gender determinate individuals (A) in the 2 hybrid zones (north: $\mathrm{n}=223$ and south: $\mathrm{n}=353$ ) and regions of Hokkaido dominated by M. galloprovincialis (west: $\mathrm{n}=302$ ) and $M$. trossulus (east: $\mathrm{n}=159$ ), and $(\mathrm{B})$ as its multi-locus genotype ( $M$. galloprovincialis, $M$. trossulus, $\mathrm{F}_{1}$ hybrid, and other hybrid) in the northern ( $\mathrm{n}=112,43,53$, and 15, respectively) and southern $(\mathrm{n}=115,7,201$, and 30 , respectively) hybrid zones

$\mathrm{p}=0.770)$ or southern $(G=1.0, \mathrm{df}=1, \mathrm{p}=0.315)$ hybrid zones (Fig. 2B). The frequency of gender determinate individuals classified as $M$. galloprovincialis and $M$. trossulus in the hybrid zones was similar to or greater than that observed in the geographic regions dominated by each of these species (Fig. 2).

Two sites, NP and TO, were re-sampled after 4 wk to determine whether the high frequency of gender indeterminate mussels at these locations could be due to a delay in the reproductive cycle compared to other regions. At NP, there was no significant difference in the frequency of gender determinate individuals between the 2 samples spaced by $4 \mathrm{wk}(G=1.75$, $\mathrm{df}=$ $1, p=0.185)$. On the other hand, at $T O$, there was a significant decline in the frequency of gender determinate individuals $(G=16.6, \mathrm{df}=1, \mathrm{p}<0.001$ ) from 65 to $14 \%$. The genetic composition of the 2 samples from NP was not significantly different $(G=3.45$, df $=3, \mathrm{p}=$ 0.327 ) but the later sample from TO had a significantly 
higher frequency of hybrids (from 46 to $86 \%$ ) ( $G=$ 13.14, $\mathrm{df}=3, \mathrm{p}=0.001$ ). Thus, there was no evidence that the low frequency of gender determinate individuals at these sites was due to retardation of the reproductive cycle, but instead, the data from TO endorse the finding that hybrids have a depressed frequency of gender determinate individuals.

\section{Histological analysis}

The field studies suggested that gender indeterminate individuals may be sterile, so we used histological analysis to assess gender and to quantify the commitment to reproduction of hybrids relative to mussels classified as pure species. These analyses were restricted to mussels collected from the southern Hokkaido hybrid zone since these populations had high frequencies of hybrids as well as pure types. We analyzed a total of 11 (5 females and 6 males) Mytilus trossulus, 11 (4 female and 7 male) M. galloprovincialis, 12 (6 females and 6 males) $F_{1}$ hybrid, and 7 (2 females and 5 males) other hybrid gender determinate individuals. We also analyzed $10 \mathrm{~F}_{1}$ hybrid and 11 other hybrid gender indeterminate individuals. Histological analysis showed that all 21 of these hybrid indeterminate individuals were male. One other individual, classified as an $\mathrm{F}_{1}$ hybrid, contained no gametic tissue whatsoever and thus could not be assigned a gender. This individual was excluded from subsequent analyses since the absence of gametic tissue often indicates the presence of a castrating parasitic infection (Hilbish \& Zimmerman 1988). There was only one gender indeterminate $M$. galloprovincialis individual within the specified location. Histological analysis showed this individual to be male. In the southern coast, there were no gender indeterminate $M$. trossulus individuals.

The thickness of the mantle also did not depend upon whether the gender of the individual could be determined in the field $\left(F_{(1,60)}=0.037, \mathrm{p}=0.848\right)$ or upon the genealogical classification of the individual $\left(F_{(3,59)}=1.452, \mathrm{p}=0.237\right)$. There was no significant effect of gender on the thickness of the mantle $\left(F_{(1,60)}=\right.$ 0.001, $\mathrm{p}=0.968$ ).

We used two-way ANOVA to test for the effects of genealogical class and gender on the variation in gamete volume fraction. GVF depended upon genealogical class $\left(F_{(3,55)}=10.71, \mathrm{p}<0.001\right)$, gender $\left(F_{(1,55)}=19.37, \mathrm{p}<0.001\right)$, and their interaction $\left(F_{(3,55)}=\right.$ 3.67, $\mathrm{p}=0.018$ ). In general, males had greater GVF than females, but the difference in Mytilus trossulus was not significant. Since our primary interest was in the effects of genealogical class on GVF, we combined the results from males and females and reanalyzed the data using single-factor ANOVA. GVF was signifi- cantly dependent upon genealogical classification $\left(F_{(3,59)}=4.38, \mathrm{p}=0.008\right)$, but the difference was due entirely to $M$. trossulus individuals having a slightly greater GVF than M. galloprovincialis and the 2 hybrid groups (Fig. 3A). Bonferroni adjusted post-hoc tests
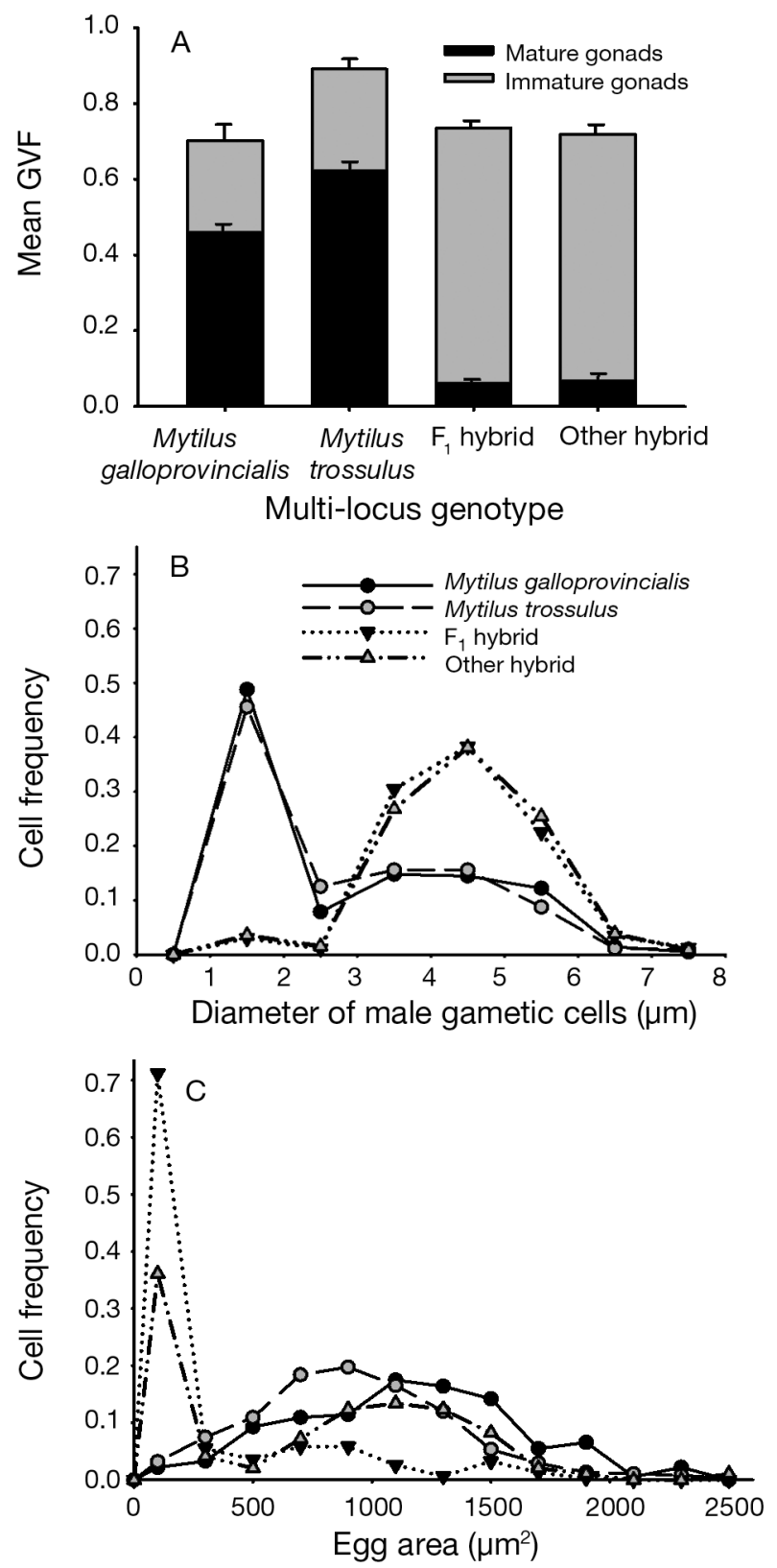

Fig. 3. Mytilus galloprovincialis and M. trossulus. Histological analysis of gametogenic activity in mussels of different multilocus genotypes (M. galloprovincialis, M. trossulus, $\mathrm{F}_{1}$ hybrid, and other hybrid) from the southern hybrid zone in Hokkaido, Japan in 2008. (A) Mean gamete volume fraction (GVF) of mature and immature gametes. Error bars: $1 \mathrm{SE}$ from the mean $(\mathrm{n}=12,11,22$, and 18, respectively); (B) Size-distribution frequency of male gametic cells, measured in cell diameter $(\mu \mathrm{m})(\mathrm{n}=528,623,1462$, and 1181, respectively); and $(\mathrm{C})$ Female gametic cells, measured as egg area $\left(\mu m^{2}\right)(n=183$, 375,309 , and 97 , respectively) 
indicated that there was no significant difference in GVF among $M$. galloprovincialis, $\mathrm{F}_{1}$ hybrids, and other hybrids. There was also no significant difference in GVF between gender determinate $(\mathrm{GVF}=0.738)$ and indeterminate individuals $(\mathrm{GVF}=0.775)\left(F_{(1,63)}=\right.$ 1.005, $\mathrm{p}=0.320$ ).

While there were no strong differences among the 4 genealogical categories in GVF, there were striking differences in the frequency of mature gametes. Both Mytilus trossulus and M. galloprovincialis had much greater levels of mature gametes and fewer immature gametes than did $F_{1}$ and other hybrids $\left(F_{(3,59)}=42.98\right.$, $\mathrm{p}<0.001$ ) (Fig. 3A). On the other hand, hybrids $\left(\mathrm{F}_{1}\right.$ and other hybrids) mostly contained immature gametes and had a very small fraction of mature gametes (Fig. 3A). Bonferroni adjusted post-hoc tests showed no significant difference between $M$. galloprovincialis and $M$. trossulus in the ratio of mature and immature gametes. Likewise, there was also no significant difference between $F_{1}$ and other hybrids in reference to the maturity of the gametes. Gender indeterminate individuals contained almost exclusively immature gametes ( $98 \%$ of all gametes). In contrast, gender determinate individuals contained similar amounts of mature $(\sim 45 \%)$ and immature gametes ( 55\%).
Both male and female hybrid ( $F_{1}$ or other hybrids) individuals exhibited unusual cells within the reproductive follicles that did not appear in the homozygous individuals. These cells appear to be arrested (Fig. 4), and did not complete development into mature gametes. In males of both Mytilus galloprovincialis and $M$. trossulus, $\sim 45 \%$ of all gametes appeared to be mature spermatozoa that average about $1.5 \mu \mathrm{m}$ in diameter (Fig. 3B), many of which had apparent flagella (Fig. 4A). The remainder of the cells appeared to be spermatogonia that are 3 to $6 \mu \mathrm{m}$ in diameter. In both $\mathrm{F}_{1}$ and other hybrid males, however, only $5 \%$ of gametes had developed into spermatozoa and $95 \%$ of the cells were $>3 \mu \mathrm{m}$ in diameter (Fig. 3B). Many of these larger cells have nuclei that appeared to contain chromosomal bodies (Fig. 4B) suggesting that these cells may arrest during meiosis as spermatocytes. Typically meiosis and the reduction in cytoplasm that occur during the transition from spermatogonia (4 to $8 \mu \mathrm{m}$ in diameter) to spermatid ( 2.5 $\mu \mathrm{m})$ are very rapid, and transitional spermatocytes (3 to $4 \mu \mathrm{m}$ ) are rarely observed (Degaulejac et al. 1995). In male $\mathrm{F}_{1}$ and other hybrids, $\sim 30 \%$ of all gametic cells were 3 to $4 \mu \mathrm{m}$ in diameter (Fig. 3B), which again suggests spermatogenesis is arresting at meiosis leading to the accumulation of spermatocytes.

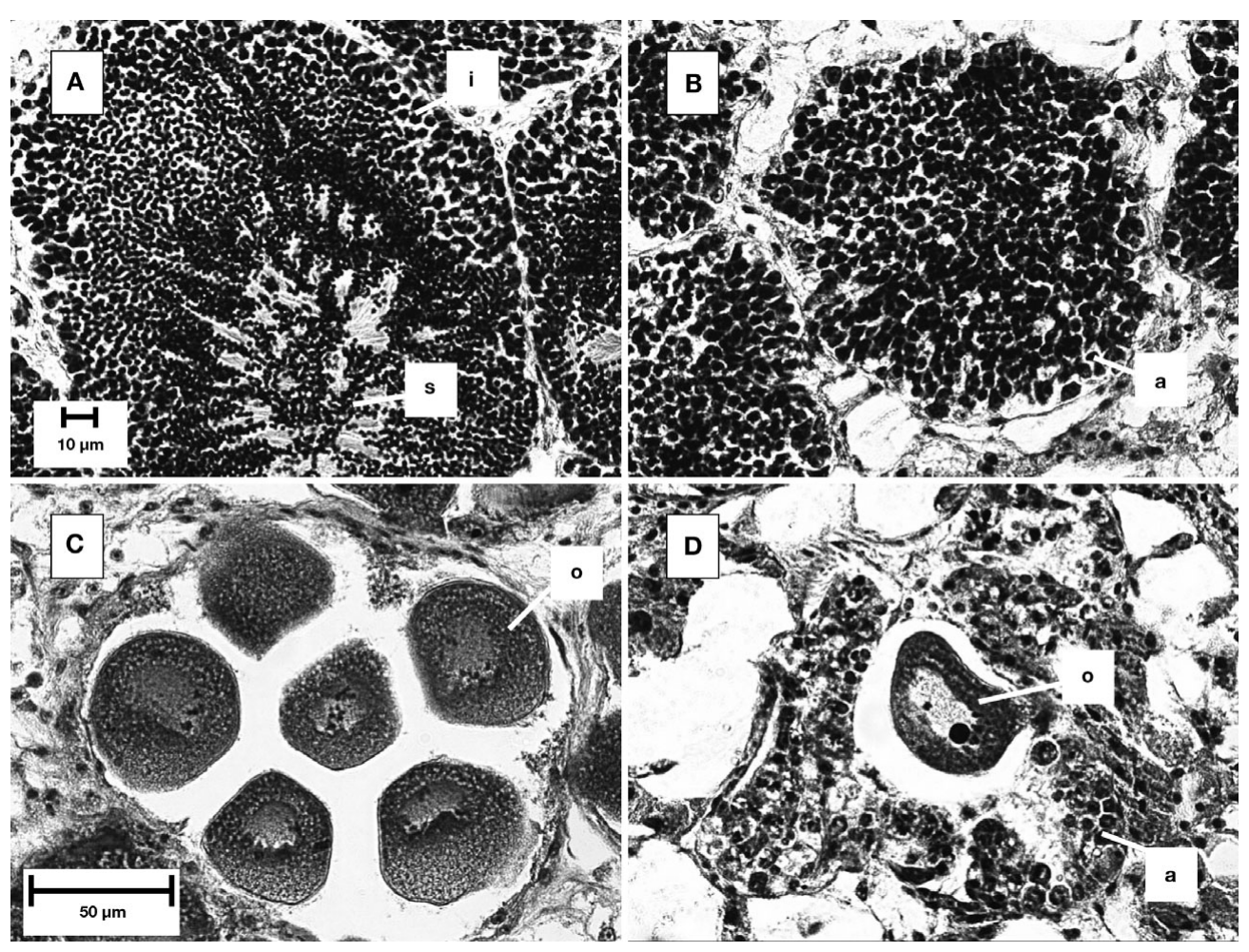

Fig. 4. Mytilus spp. Photographs of typical gonad sections of (A) male and (C) female M. galloprovincialis, and (B) male and (D) female $\mathrm{F}_{1}$ hybrids. $\mathrm{o}=$ ooyctes, $\mathrm{a}=$ arrested cells, $\mathrm{i}=$ immature male gametes, $\mathrm{s}=$ mature spermatozoa. All images are at $400 \times$ magnification 
Measuring cell size during oogenesis is more problematic because histological slices are unlikely to occur through the equator of the cell, leading to underestimation of cell size. Also, mature oocytes are often densely packed within follicles and compressed, yielding oval rather than spherical shapes. Despite these problems, there were striking differences in the size of gametogenic cells in female Mytilus galloprovincialis and $M$. trossulus compared to $F_{1}$ and other hybrids (Fig. 4). In the pure species, most gametes were 750 to $1500{\mu \mathrm{m}^{2}}^{2}$ in area, and $<10 \%$ were under $500 \mu^{2}$ (Fig. 3C). In $F_{1}$ hybrids, $>75 \%$ of all gametes were $<500 \mu^{2}$, and $70 \%$ were $<100 \mu^{2}$ in area (Fig. 3C). In other hybrid females, $\sim 40 \%$ of gametes were $<500 \mu^{2}$, and $36 \%$ were $<100 \mu^{2}$ (Fig. 3C). These data suggest that oogenesis arrested early in or prior to vitellogenesis. As with the males, many of these arrested cells appeared to have nuclei containing chromosomal bodies (Fig. 4D).

\section{DISCUSSION}

In both the northern and southern Hokkaido hybrid zones, individuals that were gender indeterminate were much more common than in regions where either Mytilus galloprovincialis or $M$. trossulus dominated (Figs. 1 \& 2A). Within populations from the hybrid zones, the inability to distinguish gender was strongly associated with hybrid individuals while mussels classified as either of the parent species were typically gender determinate. Histological analysis revealed that gender indeterminate individuals were undergoing gametogenesis at levels comparable to gender determinate individuals, but that both male and female hybrids were arresting gametogenesis prior to the formation of mature gametes. As a result of arrested gametogenesis, the gonad squash method used in the field was biased against the correct assignment of gender in males since this depends upon the presence of motile sperm, which were in very low abundance in hybrids. On the other hand, even the low incidence of mature eggs among hybrid females was readily detectable on gonad squashes. This bias is the most likely explanation for why all of the gender indeterminate individuals chosen for histological analysis $(\mathrm{n}=$ 22) turned out to be male.

An alternative explanation to arrested gametogenesis to explain the disparity in gender determination between parental and hybrid individuals would be if the 2 groups had distinct reproductive cycles such that many hybrids were not sufficiently mature to determine gender at the time we sampled. In other words, either hybrids had already spawned or had not yet begun gametogenesis such that they contained insuffi- cient gametes for sex to be determined using gonad squashes in the field. This alternative is extremely improbable. First, hybrid individuals had high GVF (Fig. 3A) and gonad thickness comparable to that observed in individuals classified as Mytilus trossulus and M. galloprovincialis. Second, even after re-sampling TO and NP a month later, gender determination of individuals was still low at both populations. Furthermore, at $\mathrm{TO}$, the proportion of gender determinate individuals in the second collection was significantly lower than the initial sample. Finally, hybrid individuals in Hokkaido contained a large proportion of cell types that we have not previously observed in mussels with similar high levels of GVF (Newell et al. 1982, Hilbish \& Zimmerman 1988). All of the data indicate that hybrids are undergoing levels of gametogenesis comparable in magnitude and timing to the parental species, but are failing to develop mature gametes successfully.

The arrest of gametogenesis occurred in both $\mathrm{F}_{1}$ and other hybrids, resulting in very low fertility in both males and females. Since arrested gametogenesis afflicted both sexes and occurred in $\mathrm{F}_{1}$ hybrids as well as their progeny (other hybrids), this reduction in fertility represents a formidable level of post-zygotic reproductive isolation. Our results indicate that hybrid mussels produce $\sim 10 \%$ of the mature gametes of either of the pure species. Such a high level of sterility in both $\mathrm{F}_{1}$ and other hybrids would severely limit, but not eliminate, introgression between Mytilus galloprovincialis and $M$. trossulus. There have been no previous reports of reduced fertility as a result of hybridization among any of the species in the blue mussel species complex. It is, however, unlikely that hybrid sterility is the only form of reproductive isolation operating between these species. All other cases of hybridization between these 2 species also result in a low frequency of hybrids (Rawson et al. 1999, Anderson et al. 2002, Wonham 2004, Elliott et al. 2008), but the Hokkaido hybrid zones are unusual in that they include very high frequencies of putative $F_{1}$ hybrids (Brannock et al. 2009) while they are rare in other hybrid zones. This suggests that typically $F_{1}$ hybrids are only rarely formed between these 2 species or have low viability and that neither mechanism is operating in Hokkaido. Other possible mechanisms of isolation include asynchrony in the reproductive cycles of the parent species, incompatibility in gamete recognition, and inviability of $F_{1}$ hybrids. All of these mechanisms are known to occur between other pairs of hybridizing blue mussels. Gilg et al. (2007) demonstrated that M. edulis and M. galloprovincialis have distinct reproductive cycles in a hybrid zone in England, and Toro et al. (2002) found evidence for reproductive asynchrony between $M$. edulis and $M$. trossulus in Newfoundland. Gamete 
recognition incompatibility has been documented between $M$. trossulus and $M$. edulis (Rawson et al. 2003, Toro et al. 2006, Slaughter et al. 2008), and $M$. edulis and M. galloprovincialis (Bierne et al. 2002). Hybrids of $M$. trossulus and $M$. edulis also have elevated rates of larval developmental abnormalities (Toro et al. 2006), and larvae of hybrids between $M$. edulis and $M$. galloprovincialis have reduced growth rate and viability (Bierne et al. 2002, Beaumont et al. 2004). However, potential isolating barriers between M. galloprovincialis and $M$. trossulus have rarely been examined. Beaumont et al. (2005) report the absence of any fundamental fertilization barrier between these species and no clear difference in the growth of hybrid larvae compared to larvae of $M$. galloprovincialis and M. trossulus from the Baltic. Matson et al. (2003) found $\mathrm{F}_{1}$ hybrid larvae did not grow or survive substantially differently than did larvae from M. galloprovincialis or M. trossulus from the Pacific. Of all potential mechanisms for reproductive isolation described among pairs of blue mussels, the hybrid sterility documented here is the strongest known, representing a 10-fold decrease in the success of hybrids relative to their parent taxa.

High levels of hybrid sterility suggest the 2 hybrid zones in Hokkaido represent classic tension zones (Barton \& Hewitt 1985) in which hybrid fitness is a function of the individual's genetic composition rather than reflecting a mosaic distribution of environmental variation. Tension zones are expected to be especially responsive to changes in the relative abundance and performance of the parent taxa, and tend to migrate away from the more successful taxon (Barton \& Hewitt 1985). We therefore expect that the geographic stability of the hybrid zones in Japan would be low, and that their positions should change in response to fluctuating environmental conditions that favor one or the other parental species. Hilbish et al. (2010) have shown that a hybrid zone between Mytilus galloprovincialis and $M$. trossulus on the coast of California has rapidly changed position in an apparent response to regional cooling and increased recruitment success of $M$. trossulus larvae. It is not presently known whether hybrids between these species in the eastern Pacific also show substantially reduced fertility, but the dynamics of the hybrid zone in California suggest that it may behave as a tension zone. Future studies should assess whether hybrid infertility is a general feature of these hybrid zones formed between M. galloprovincialis and $M$. trossulus.

Detailed studies of other, primarily terrestrial, hybrid zones have typically shown them to be generated and maintained by eclectic arrays of evolutionary forces; thus, hybrid zones formed between the same species in different locations or between different combinations of closely related species may have different fates and architectures (Arnold 1997). Hybridization between Mytilus trossulus and M. galloprovincialis also appears to be influenced by a variable interplay of forces. On the one hand, this study demonstrates that hybrid sterility is likely a potent form of post-zygotic isolation that limits introgression in both hybrid zones formed in northern Japan. Since introgression is similarly limited in other hybrid zones formed between these 2 species (Rawson et al. 1999, Anderson et al. 2002), it seems likely that hybrid sterility also plays a role in shaping these hybrid zones. On the other hand, the southern hybrid zone in Hokkaido is characterized by an exceptionally high frequency of $F_{1}$ hybrids that is not observed in northern Hokkaido (Brannock et al. 2009) or in other hybrid zones formed between these 2 species (Rawson et al. 1999, Anderson \& Thompson 2002). This suggests that in southern Hokkaido there is either a greater propensity for hybridization in the first place or that $F_{1}$ hybrids have greater viability than parental types (Brannock et al. 2009), but either way, these forces do not appear to be prevalent features of other hybrid zones formed between $M$. trossulus and M. galloprovincialis (Rawson et al. 1999, Anderson et al. 2002) or between other combinations of Mytilus spp. (Wilhelm \& Hilbish 1998, Rawson et al. 2001, Toro et al. 2004, Riginos \& Cunningham 2005). Thus, like many other hybrid zones (Arnold 1997), these appear to be formed and maintained by a complex interplay of forces, some of which vary in intensity in different locations and depend upon exactly which combination of species hybridize.

Mytilus galloprovincialis is a highly invasive species (Lowe et al. 2000, Branch \& Steffani 2004, Robinson et al. 2005) and is frequently introduced through human activities (Geller et al. 1994, Anderson et al. 2002). Hybridization with $M$. trossulus or other endemic mussel species is a potentially destructive form of genetic pollution in addition to the direct ecological consequences of invasion. On the other hand, introgression could conceivably result in a diminution of the traits that make M. galloprovincialis competitively dominant and thus lessen the impact of its invasion. If the hybrid infertility documented here is general, then it provides a significant, but imperfect, impediment to genetic pollution of $M$. trossulus by hybridization with $M$. galloprovincialis. Even with a 10-fold decrease in fertility of both $F_{1}$ and other hybrids, introgression will still occur between $M$. galloprovincialis and $M$. trossulus albeit at a much retarded rate. For example, a simple model that assumes an initial 1:1 frequency of the 2 species, random mating, and no fitness differences among the parent taxa, $F_{1}$ and other hybrids result in $>98 \%$ of all individuals being 'other hybrids' within 3 generations. The same model with $\mathrm{F}_{1}$ and other hybrids having $10 \%$ of the fertility of the parent types only produces $23 \%$ 
'other hybrids' in the same number of generations, and the rate of introgression progressively and dramatically declines with additional generations. Thus, the ecological consequences of invasion by $M$. galloprovincialis are more likely to outweigh the effects of introgression. However, it is important to note that at this time we do not know whether the hybrid infertility we have documented in Hokkaido is a general mechanism of post-zygotic isolation between these taxa, whether it can be modified by local environmental circumstances, or whether some recombinant genotypes are more prone to allow introgression than others.

Acknowledgements. We thank C. R. Zimmermann for her assistance with field and laboratory work. We are extremely appreciative to Y. Kuwahara, M. Murooka, and the Muroran Marine Station for their willingness to share supplies, knowledge, and time while in Japan. We are grateful to S.A. Woodin for the use of her microscope and to R. M. Showman and R. H. Sawyer for their advice on histological analysis and interpretation. We thank F. P. Lima for his assistance in the preparation of Fig. 1. We also appreciate the critical comments made by anonymous reviewers that improved the quality of this paper. This research was funded by NASA (NNG04GE43G and NNX07AF20G) and NOAA (NA04NOS4780264) grants awarded to T.J.H. and the Elsie Taber Graduate Fellowship and Slocum-Lunz Foundation Fellowship awarded to P.M.B.

\section{LITERATURE CITED}

Anderson EC, Thompson EA (2002) A model-based method for identifying species hybrids using multilocus genetic data. Genetics 160:1217-1229

Anderson AS, Bilodeau AL, Gilg MR, Hilbish TJ (2002) Routes of introduction of the Mediterranean mussel (Mytilus galloprovincialis) to Puget Sound and Hood Canal. J Shellfish Res 21:75-79

Arnold ML (1997) Natural hybridization and evolution. Oxford University Press, New York, NY

Barton NH (1979) The dynamics of hybrid zones. Heredity 43: 341-359

Barton NH, Hewitt GM (1985) Analysis of hybrid zones. Annu Rev Ecol Syst 16:113-148

Beaumont AR, Turner G, Wood AR, Skibinski DOF (2004) Hybridisations between Mytilus edulis and Mytilus galloprovincialis and performance of pure species and hybrid veliger larvae at different temperatures. J Exp Mar Biol Ecol 302:177-188

Beaumont AR, Turner G, Wood AR, Skibinski DOF (2005) Laboratory hybridizations between Mytilus species and performance of pure species and hybrid veliger larvae at lowered salinity. J Molluscan Stud 71:303-306

Beaumont AR, Hawkins MP, Doig FL, Davies IM, Snow M (2008) Three species of Mytilus and their hybrids identified in a Scottish Loch: natives, relicts and invaders? J Exp Mar Biol Ecol 367:100-110

Bierne N, David P, Boudry P, Bonhomme F (2002) Assortative fertilization and selection at larval stage in the mussels Mytilus edulis and M. galloprovincialis. Evolution 56: 292-298

Boecklen WJ, Howard DJ (1997) Genetic analysis of hybrid zones: numbers of markers and power of resolution. Ecology 78:2611-2616
Branch GM, Steffani CN (2004) Can we predict the effects of alien species? A case-history of the invasion of South Africa by Mytilus galloprovincialis (Lamarck). J Exp Mar Biol Ecol 300:189-215

Brannock PM, Wethey DS, Hilbish TJ (2009) Extensive hybridization with minimal introgression in Mytilus galloprovincialis and $M$. trossulus in Hokkaido, Japan. Mar Ecol Prog Ser 383:161-171

> Comesaña AS, Toro JE, Innes DJ, Thompson RJ (1999) A molecular approach to the ecology of a mussel (Mytilus edulis $M$. trossulus) hybrid zone on the east coast of Newfoundland, Canada. Mar Biol 133:213-221

> de Gaulejac B, Henry M, Vicente N (1995) An ultrastructural study of gametogenesis of the marine bivalve Pinna nobilis (Linnaeus 1758) II. Spermatogenesis. J Molluscan Stud 61:393-403

- Elliott J, Holmes K, Chambers R, Leon K, Wimberger P (2008) Differences in morphology and habitat use among the native mussel Mytilus trossulus, the non-native M. galloprovincialis, and their hybrids in Puget Sound, Washington. Mar Biol 156:39-53

Elston RA, Moore JD, Brooks K (1992) Disseminated neoplasia of bivalve molluscs. Rev Aquat Sci 65:405-466

- Fisher C, Skibinski DOF (1990) Sex biased mitochondrial DNA heteroplasmy in the marine mussel Mytilus. Proc Biol Sci 242:149-156

Geller JB, Carlton JT, Powers DA (1994) PCR-based detection of mtDNA haplotypes of native and invading mussels on the northeastern Pacific coast: latitudinal pattern of invasion. Mar Biol 119:243-249

Gilg MR, Kirby SE, Sullivan R, Knapp LW, Hilbish TJ (2007) Dispersal vs. retention: correspondence of species-specific reproductive cycles and settlement periods in a blue mussel hybrid zone. Mar Ecol Prog Ser 351:151-161

Gosling EM (1992) Systematics and geographic distribution of Mytilus. In: Gosling EM (ed) The mussel Mytilus: ecology, physiology, genetics and culture. Elsevier, New York, NY, p 1-20

Harrison RG, Rand DM (1989) Mosaic hybrid zones and the nature of species boundaries. In: Otte D, Endler JA (eds) Speciation and its consequences. Sinauer Associates, Sunderland, MA, p 111-133

Heath DD, Rawson PD, Hilbish TJ (1995) PCR-based nuclear markers identify alien blue mussel (Mytilus spp) genotypes on the west coast of Canada. Can J Fish Aquat Sci 52: 2621-2627

Hilbish TJ, Zimmerman KM (1988) Genetic and nutritional control of the gametogenic cycle in Mytilus edulis. Mar Biol 98:223-228

- Hilbish TJ, Brannock PM, Jones KR, Smith AB, Bullock BN, Wethey DS (2010) Historical changes in the distributions of invasive and endemic marine invertebrates are contrary to global warming predictions: the effects of decadal climate oscillations. J Biogeogr 37:423-431

Inoue K, Waite JH, Matsuoka M, Odo S, Harayama S (1995) Interspecific variations in adhesive protein sequences of Mytilus edulis, M. galloprovincialis, and M. trossulus. Biol Bull 189:370-375

Inoue K, Odo S, Noda T, Nakao S and others (1997) A possible hybrid zone in the Mytilus edulis complex in Japan revealed by PCR markers. Mar Biol 128:91-95

> Lowe DM, Moore MN, Bayne BL (1982) Aspects of gametogenesis in the marine mussel Mytilus edulis L. J Mar Biol Assoc UK 62:133-145

Lowe S, Browne M, Boudjelas S, De Poorter M (2000) 100 of the world's worst invasive alien species. A selection from the Global Invasive Species Database (IUCN), Hollands Printing, Auckland 
Matson SE, Davis JP, Chew KK (2003) Laboratory hybridization of the mussels, Mytilus trossulus and M. galloprovincialis: larval growth, survival and early development. J Shellfish Res 22:423-430

McCartney MA, Lessios HA (2002) Quantitative analysis of gametic incompatibility between closely related species of neotropical sea urchins. Biol Bull 202:166-181

McDonald JH, Koehn RK (1988) The mussels Mytilus galloprovincialis and Mytilus trossulus on the Pacific Coast of North America. Mar Biol 99:111-118

Moore WS (1977) Evaluation of narrow hybrid zones in vertebrates. Q Rev Biol 52:263-277

Nason JD, Ellstrand NC (1993) Estimating the frequencies of genetically distinct classes of individuals in hybridized populations. J Hered 84:1-12

Newell RIE, Hilbish TJ, Koehn RK, Newell CJ (1982) Temporal variation in the reproductive cycle of Mytilus edulis $\mathrm{L}$ (Bivalvia, Mytilidae) from localities on the East Coast of the United States. Biol Bull 162:299-310

Palumbi SR (1992) Marine speciation on a small planet. Trends Ecol Evol 7:114-118

Palumbi SR (1994) Genetic divergence, reproductive isolation, and marine speciation. Annu Rev Ecol Syst 25: $547-572$

Peters EC (1988) Recent investigations on the disseminated sarcomas of marine bivalve molluscs. Am Fish Soc Spec Pub 18:74-92

Rawson PD, Hilbish TJ (1998) Asymmetric introgression of mitochondrial DNA among European populations of blue mussels (Mytilus spp.). Evolution 52:100-108

Rawson PD, Joyner KL, Meetze K, Hilbish TJ (1996a) Evidence for intragenic recombination within a novel genetic marker that distinguishes mussels in the Mytilus edulis species complex. Heredity 77:599-607

Rawson PD, Secor CL, Hilbish TJ (1996b) The effects of natural hybridization on the regulation of doubly uniparental mtDNA inheritance in blue mussels (Mytilus spp). Genetics 144:241-248

Rawson PD, Agrawal V, Hilbish TJ (1999) Hybridization between the blue mussels Mytilus galloprovincialis and M. trossulus along the Pacific coast of North America: evidence for limited introgression. Mar Biol 134:201-211

Rawson PD, Hayhurst S, Vanscoyoc B (2001) Species composition of blue mussel populations in the northeastern Gulf of Maine. J Shellfish Res 20:31-38

Rawson PD, Slaughter C, Yund PO (2003) Patterns of gamete incompatibility between the blue mussels Mytilus edulis and M. trossulus. Mar Biol 143:317-325

Riginos C, Cunningham CW (2005) Local adaptation and species segregation in 2 mussel (Mytilus edulis $\times$ Mytilus trossulus) hybrid zones. Mol Ecol 14:381-400

Editorial responsibility: Hans Heinrich Janssen, Oldendorf/Luhe, Germany
Riginos C, McDonald JH (2003) Positive selection on an acrosomal sperm protein, M7 lysin, in three species of the mussel genus Mytilus. Mol Biol Evol 20:200-207

> Riginos C, Wang D, Abrams AJ (2006) Geographic variation and positive selection on M7 lysin, an acrosomal sperm protein in mussels (Mytilus spp.). Mol Biol Evol 23: 1952-1965

Robinson TB, Griffiths CL, McQuaid C, Rius M (2005) Marine alien species of South Africa: status and impacts. Afr J Mar Sci 27:297-306

Skurikhina LA, Kartavtsev YF, Chichvarkhin AY, Pan'kova MV (2001) Study of two species of mussels, Mytilus trossulus and Mytilus galloprovincialis (Bivalvia, Mytilidae), and their hybrids in Peter the Great Bay of the Sea of Japan with the use of PCR markers. Russ J Genet 37:1448-1451

Slaughter C, McCartney MA, Yund PO (2008) Comparison of gamete compatibility between two blue mussel species in sympatry and in allopatry. Biol Bull 214:57-66

Sokal R, Rohlf F (1995) Biometry: the principles and practice of statistics in biological research. W.H. Freeman, New York, NY

Springer SA, Crespi BJ (2007) Adaptive gamete-recognition divergence in a hybridizing Mytilus population. Evolution 61:772-783

Styan CA, KupriyANOVA E, Havenhand JN (2008) Barriers to cross fertilization between populations of a widely dispersed polychaete species are unlikely to have arisen through gametic compatibility arms races. Evolution 62:3041-3055

Swanson WJ, Vacquier VD (2002) The rapid evolution of reproductive proteins. Nat Rev Genet 3:137-144

Toro JE, Thompson RJ, Innes DJ (2002) Reproductive isolation and reproductive output in two sympatric mussel species (Mytilus edulis, M. trossulus) and their hybrids from Newfoundland. Mar Biol 141:897-909

Toro J, Innes DJ, Thompson RJ (2004) Genetic variation among life-history stages of mussels in a Mytilus edulis- $M$. trossulus hybrid zone. Mar Biol 145:713-725

Toro JE, Thompson RJ, Innes DJ (2006) Fertilization success and early survival in pure and hybrid larvae of Mytilus edulis (Linnaeus, 1758) and M. trossulus (Gould, 1850) from laboratory crosses. Aquacult Res 37:1703-1708

Wilhelm R, Hilbish TJ (1998) Assessment of natural selection in a hybrid population of mussels: evaluation of exogenous vs. endogenous selection models. Mar Biol 131:505-514

Wonham MJ (2004) Mini-review: distribution of the Mediterranean mussel Mytilus galloprovincialis (Bivalvia: Mytilidae) and hybrids in the Northeast Pacific. J Shellfish Res 23:535-543

Zouros E, Ball AO, Saavedra C, Freeman KR (1994) An unusual type of mitochondrial-DNA inheritance in the blue mussel Mytilus. Proc Natl Acad Sci USA 91:7463-7467

Submitted: October 30, 2009; Accepted: February 1, 2010 Proofs received from author(s): April 30, 2010 